\title{
Equilíbrio estético dentogengivofacial angariado pela gengivoplastia e aplicação de toxina botulínica
}

\author{
Dentogingivofacial esthetic balance obtained by gingivoplasty \\ and botulinum toxin application
}

\begin{abstract}
RESUMO
Introdução: Atualmente, a estética orofacial tem se tornado o objetivo principal no tratamento odontológico. O sorriso gengival é uma das queixas dos pacientes, já que tal situação pode influenciar a autoestima e o relacionamento social. A beleza do sorriso não está apenas na forma, posição e cor dos dentes, mas também nas características do tecido gengival, que devem ser tão harmoniosas quanto os dentes. O desenvolvimento de novas técnicas como a aplicação de toxina botulínica, pode ser uma opção terapêutica mais conservadora quando comparada à intervenção cirúrgica no tratamento do sorriso gengival.

Objetivo: O propósito deste trabalho é apresentar o caso de uma paciente que apresentou discrepância dentogengival e sorriso gengival, sendo tratado pela gengivoplastia e aplicação de toxina botulínica, otimizando a harmonia do sorriso e a estética facial.

Conclusões: Mesmo apresentando efeito temporário na correção do sorriso gengival, a aplicação da toxina botulínica é uma alternativa menos invasiva, rápida, segura e eficaz, que produz resultados harmônicos. A toxina botulínica é um complemento útil na melhora estética do sorriso e fornece melhores resultados quando associada à gengivoplastia, podendo ser mais uma opção terapêutica ao alcance do cirurgiãodentista, na finalização e complementação dos seus casos.

Palavras-chave: crescimento excessivo da gengiva; toxinas botulínicas tipo A; gengivoplastia; estética dentária.
\end{abstract}

\begin{abstract}
Background: Currently, the orofacial aesthetic has become the main goal in dental treatment. Gummy smile is one of the complaints from the patients, since this situation may influence the self-steem and social relationship. The beauty of the smile is not only in form, position and color of the teeth, but also in the features of gingival tissue, which should be as harmonious as the teeth. The development of new techniques, such as the application of botulinum toxin, may be a more conservative therapeutic option when compared to surgical intervention in the treatment of gummy smile.

Objective: The purpose of this paper is to present the case of a patient with discrepancy dentogingival and gummy smile, which was treated with gingivoplasty and application of botulinum toxin, optimizing the harmony of the smile and facial esthetic.

Conclusions: Even with a temporary effect on the correction of the gummy smile, the application of botulinum toxin is an alternative less invasive, fast, safe, effective and it produces harmonics results. Botulinum toxin is a useful supplement in cosmetic improvement of the smile and it gives better results when combined with gingivoplasty, and may be another therapeutic option within the reach of the dentist, in the finalization and complementation of their cases.
\end{abstract}

Keywords: gingival overgrowth; type A botulinum toxins; gingivoplasty; dental aesthetic.
Irineu Gregnanin Pedron ${ }^{1}$

Augusto Roque Neto $^{2}$

Luciano Bonatelli Bispo ${ }^{3}$

Ricardo Amore ${ }^{4}$

Caleb Shitsuka $^{5}$

1DDS, MsC. Professor das Disciplinas de Periodontia, Implantodontia, Estomatologia e Clínica Integrada, Curso de Odontologia, Universidade Brasil.

2DDS, MsC. Professor das Disciplinas de Dentística e Clínica Odontológica Integrada, Curso de Odontologia, Universidade Metodista de São Paulo.

3DDS, MsC, PhD. Professor da Disciplina de Dentística, Curso de Odontologia, Universidade Brasil.

4DDS, MsC, PhD. Professor do Curso de Especialização em Dentística, São Leopoldo Mandic. 5DDS, MsC, PhD. Professor das Disciplinas de Odontopediatria e Cariologia, Curso de Odontologia, Universidade Brasil.

Autor para correspondência:

Nome do autor: Irineu Gregnanin Pedron Endereço: Rua Flores do Piauí, 508 - São Paulo SP - CEP: 08210-200

Telefone: (11) 2944-4067

E-mail e telefone dos autores:

Irineu Gregnanin Pedron

E-mail: igpedron@alumni.usp.br

Tel.: (11) 99917-3889 / (11) 2944-4067

Submetido em: 23-6-2020

Aceito em: 21-10-2021 


\section{INTRODUÇÃO}

Atualmente, a procura por procedimentos estéticos tem crescido exponencialmente. Os procedimentos odontológicos, bem como os médicos, além de almejarem o princípio de promoção de saúde, buscam a estética do sorriso, sendo uma forma de comunicação e socialização que exprime diversos sentimentos ${ }^{1-3}$.

A harmonia estética facial correlaciona-se diretamente com o sorriso e este por sua vez é formado pela união de 3 componentes: os dentes, a gengiva e o lábio ${ }^{1-6}$. O sorriso torna-se agradável esteticamente quando estes elementos estão dispostos em proporção adequada, e a exposição do tecido gengival é limitada a $3 \mathrm{~mm}$. Quando a exposição gengival é maior que $3 \mathrm{~mm}$, caracteriza-se a condição não estética denominada sorriso gengival, que afeta psicologicamente alguns pacientes ${ }^{4-10}$.

Diversas modalidades terapêuticas foram propostas para a correção do sorriso gengival, dentre elas a gengivectomia ou gengivoplastia ${ }^{1-8,10}$, miectomia ${ }^{8,10}$ e a cirurgia ortognática ${ }^{8,10,11}$, sendo os dois últimos procedimentos mais invasivos e apresentando elevada morbidade 9 . Em contrapartida, a utilização da toxina botulínica pode ser considerada como opção terapêutica, sendo um método mais conservador, efetivo, rápido e seguro, quando comparado aos procedimentos cirúrgicos ${ }^{3,7,12}$.

A toxina botulínica é sintetizada pela bactéria Gram-positiva anaeróbica Clostridium botulinum, e atua inibindo a liberação de acetilcolina na junção neuromuscular, impedindo a contração do músculo. Existem 7 sorotipos distintos da toxina $(\mathrm{A}, \mathrm{B}, \mathrm{C} 1, \mathrm{D}$, $\mathrm{E}, \mathrm{F}$ e $\mathrm{G})^{3,8,10,11}$. Entretanto, o tipo A é o subtipo mais frequentemente utilizado na clínica e o mais potente $\mathrm{e}^{3,8}$.

Atualmente, a toxina botulínica tem se mostrado eficiente no tratamento do sorriso gengival, em pacientes com hiperfunção dos músculos envolvidos no sorriso, bem como em outras desordens como as disfunções temporomandibulares (hipertrofia do músculo masseter, bruxismo, briquismo) e a dor miofacial ${ }^{3,8,11}$. O propósito deste trabalho foi relatar o caso de uma paciente que apresentou sorriso gengival e foi tratado associando-se a gengivoplastia e a aplicação de toxina botulínica.

\section{RELATO DE CASO}

Paciente leucoderma, do gênero feminino, 32 anos de idade, compareceu à clínica particular com queixa de sorriso gengival (Figura 1).

Ao exame clínico extrabucal, foi analisada discrepância entre o comprimento dos dentes anterossuperiores e sorriso gengival proeminente (Figuras 2 e 3). O comprimento do dente 21 foi mensurado com 9,2mm (dentre a linha cervical e a borda incisal) e o sorriso gengival com 14,2mm (dentre a margem inferior do lábio superior ao sorrir, e a borda incisal do dente 21).

No exame clínico intrabucal, o dente 21 foi utilizado como referência por apresentar-se menor em comprimento em relação ao dente 11. Entretanto, todo o sextante anterossuperior apresentou-se desarmônico em relação ao comprimento dos dentes contíguos (Figura 4). A régua de proporcionalidade de Chu também indicou a desproporção entre comprimento e largura do dente 21 (Figura 5), que foi complementada pela sondagem e 


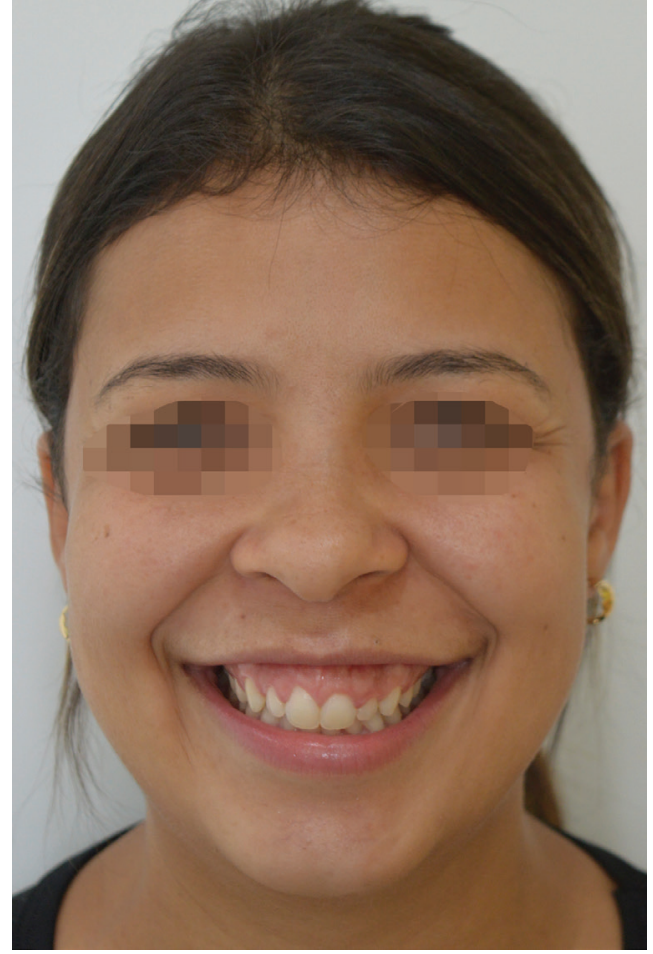

Figura 1: Paciente apresentando discrepância entre os dentes anterossuperiores e sorriso gengival.

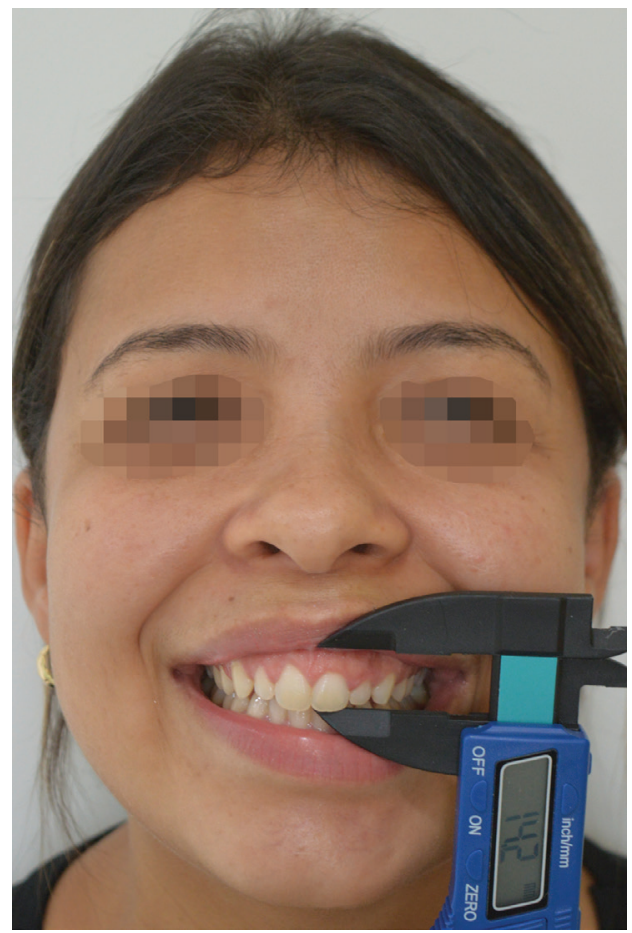

Figura 3: Sorriso gengival mensurado $(14,2 \mathrm{~mm})$ entre a margem inferior do lábio superior ao sorrir e a borda incisal do dente 21.

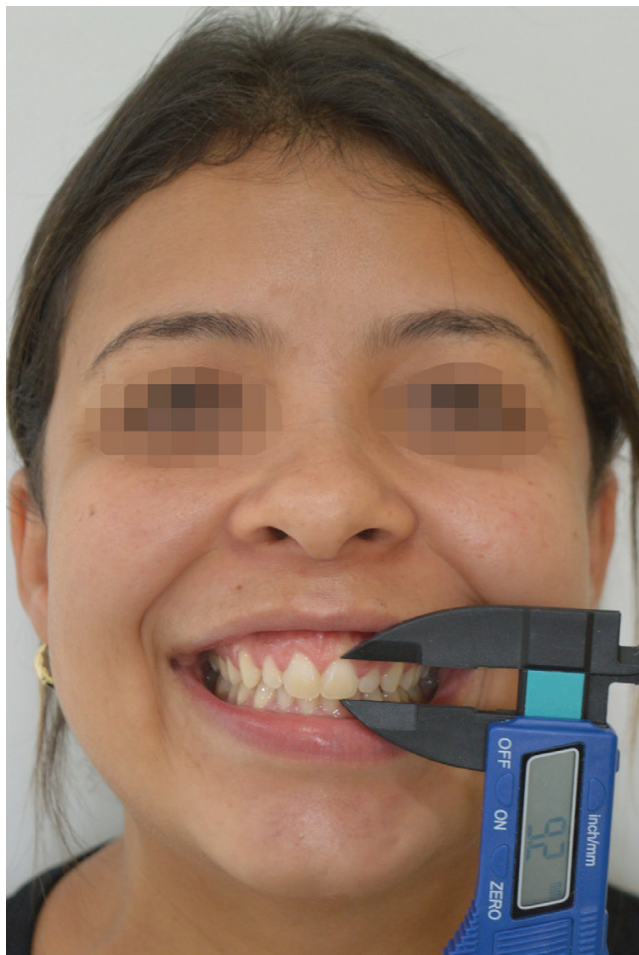

Figura 2: Discrepância entre o comprimento dos dentes anterossuperiores, e mensuração do comprimento do dente 21 (9,2mm).

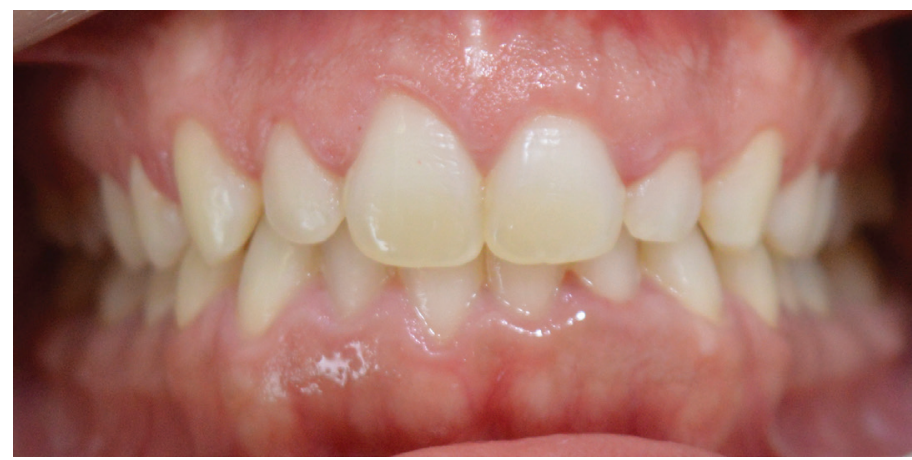

Figura 4: Aspectos clínicos intrabucais da discrepância dentogengival dos dentes anterossuperiores.

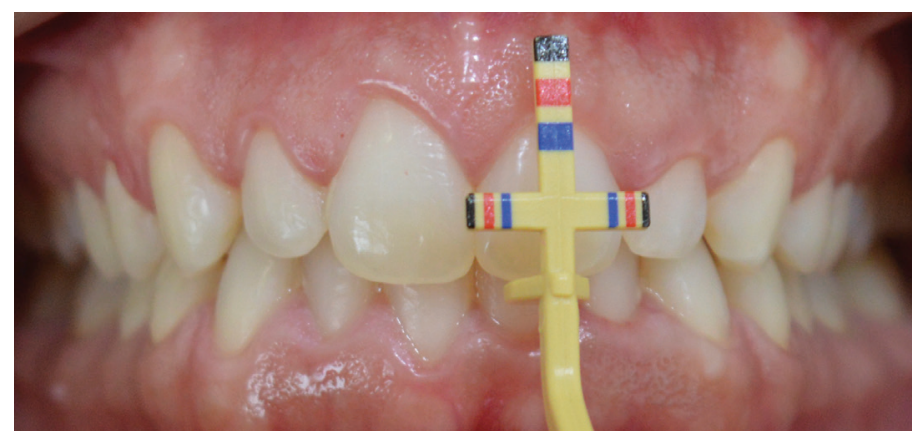

Figura 5: Dente 21 utilizado como referência apresentando a desproporção entre comprimento e largura demonstrado pela régua de proporcionalidade de Chu. 
apresentando excesso de tecido gengival (Figura 6). Adicionalmente, a exposição gengival acentuada maior de $3 \mathrm{~mm}$ foi determinante para a classificação do sorriso gengival.

Foi proposta a gengivoplastia para a redefinição dos arcos gengivais e torná-los mais harmônicos, reduzindo assim a discrepância dentogengival do sorriso gengival. A paciente concordou e assentiu à execução do tratamento. A priori, antes da gengivoplastia, foi recomendada a orientação de higiene bucal, com o propósito de reduzir a inflamação gengival e evitar a possibilidade de recorrência do crescimento gengival.

Decorridos 7 dias da consulta de orientação da higiene bucal, foi realizada a gengivoplastia. Sob anestesia local infiltrativa, foram determinados os pontos sangrantes com auxílio de sonda milimetrada e a união destes pontos foi realizada com o bisturi elétrico (BE $3000^{\circledR}, \mathrm{KVN}$, São Paulo, Brasil) ${ }^{1,2}$. O comprimento dos dentes foi aumentado, caracterizando-se o zênite dentário. Posteriormente, foi realizado, o scraping, assemelhando-se a técnica de bisel externo, com o propósito de incrementar a reparação tecidual (Figuras 7 e 8). Não houve necessidade da utilização do cimento cirúrgico, haja vista que o processo da ferida ocorre por segunda intenção. A paciente foi orientada e foram administrados fármacos analgésicos no pós-operatório.

Após 30 dias, na consulta subsequente, foi observada reparação tecidual satisfatória e não foram reportadas alterações ou queixas pela paciente (Figura 9). A Figura 10

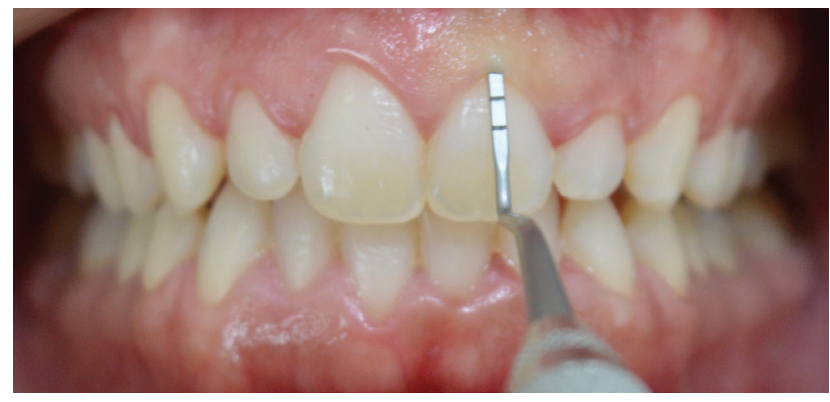

Figura 6: Sondagem apresentando excesso de tecido gengival.

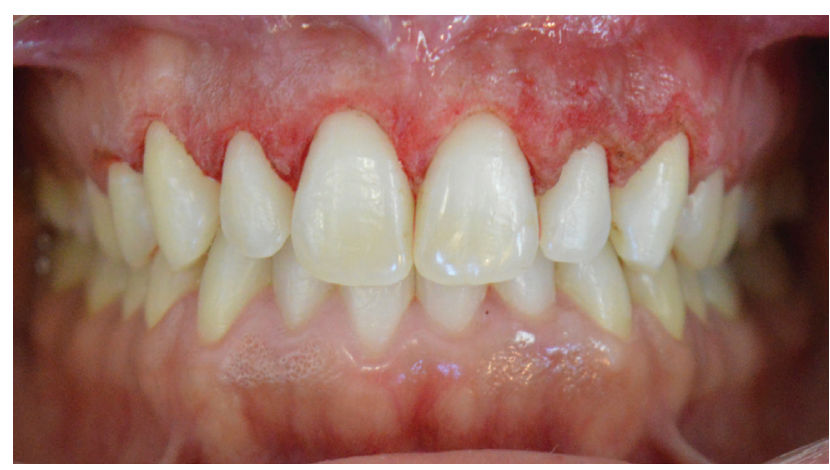

Figura 8: Pós-cirúrgico imediato após a gengivoplastia.

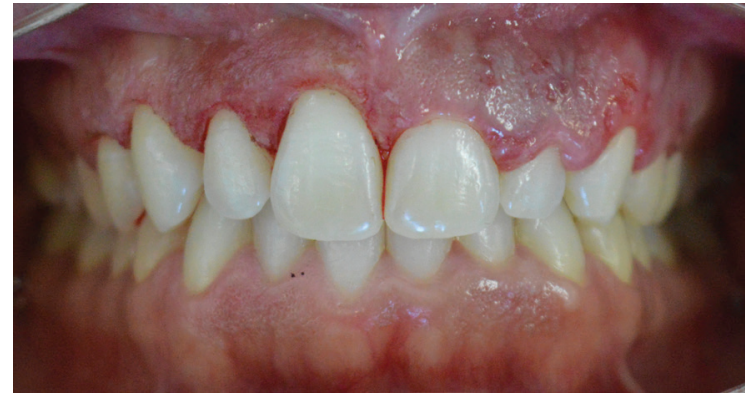

Figura 7: Pós-cirúrgico imediato do lado direito da maxila.

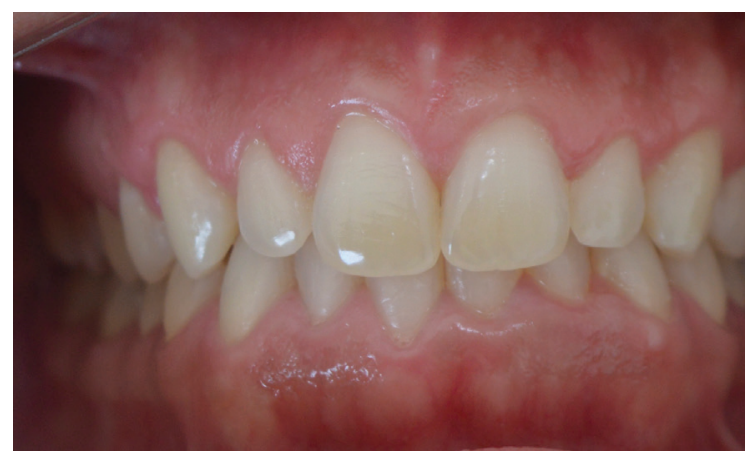

Figura 9: Reparação tecidual satisfatória (pós-cirúrgico de 30 dias). 
apresentou harmonia na relação entre comprimento e largura. Entretanto, observou-se a persistência do sorriso gengival (Figura 11). O comprimento do dente 21 tornou-se mais condizente com o comprimento do dente 11, medindo $10 \mathrm{~mm}$ (Figura 12), enquanto que o procedimento cirúrgico reduziu a discrepância do sorriso gengival (reduzindo para 12,9mm), apresentado na Figura 13.

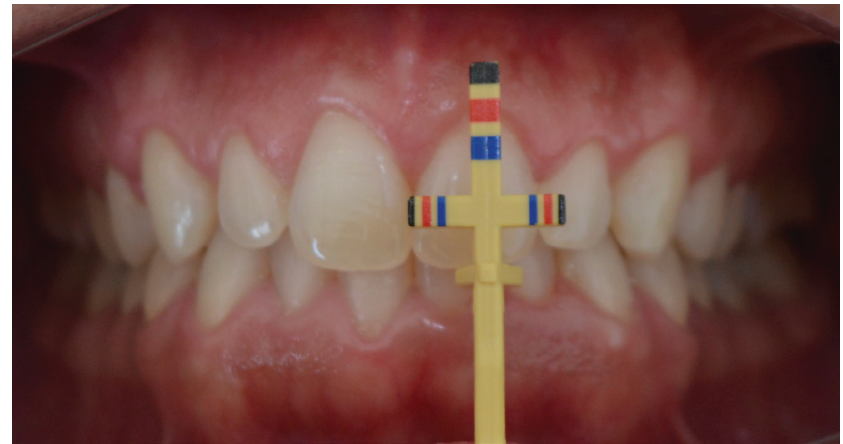

Figura 10: Harmonia na relação entre comprimento e largura do dente 21 após a gengivoplastia.

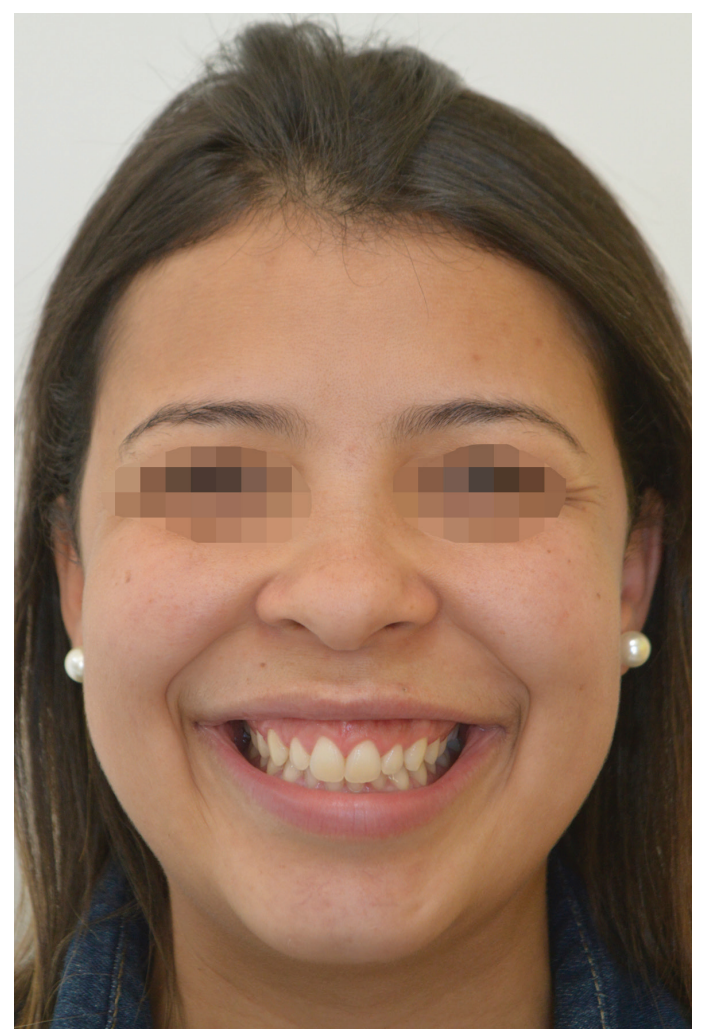

Figura 11: Harmonização dentogengivofacial angariada após a gengivoplastia, mas com a persistência do sorriso gengival.

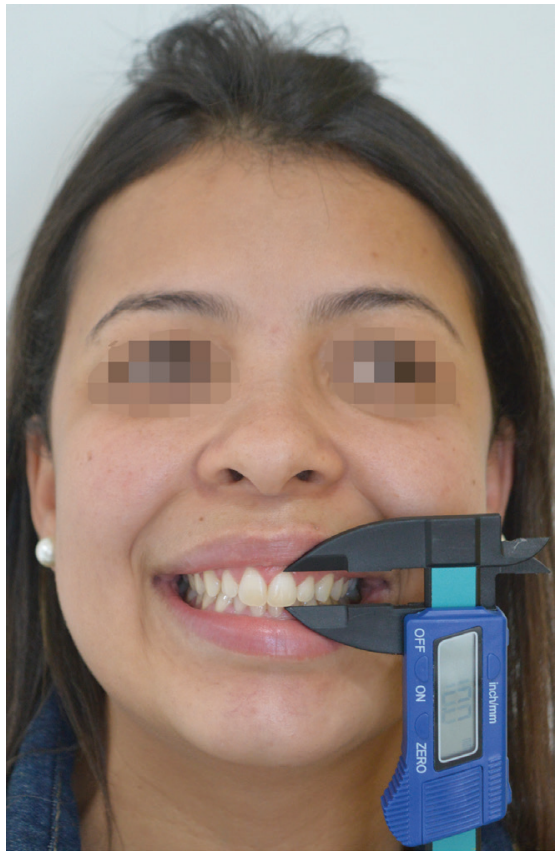

Figura 12: Aumento do comprimento do dente $21(10 \mathrm{~mm})$ após a gengivoplastia.

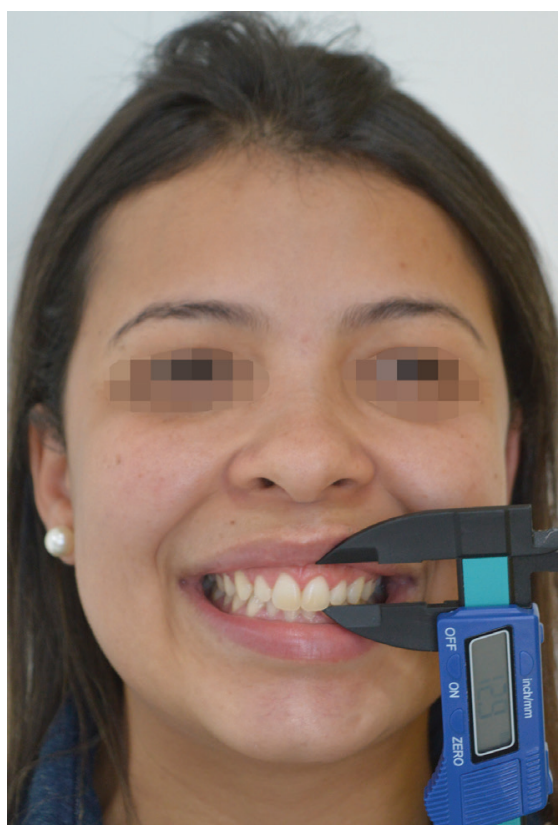

Figura 13: Melhora da relação dentogengivofacial do sorriso gengival, apresentando $12,9 \mathrm{~mm}$. 


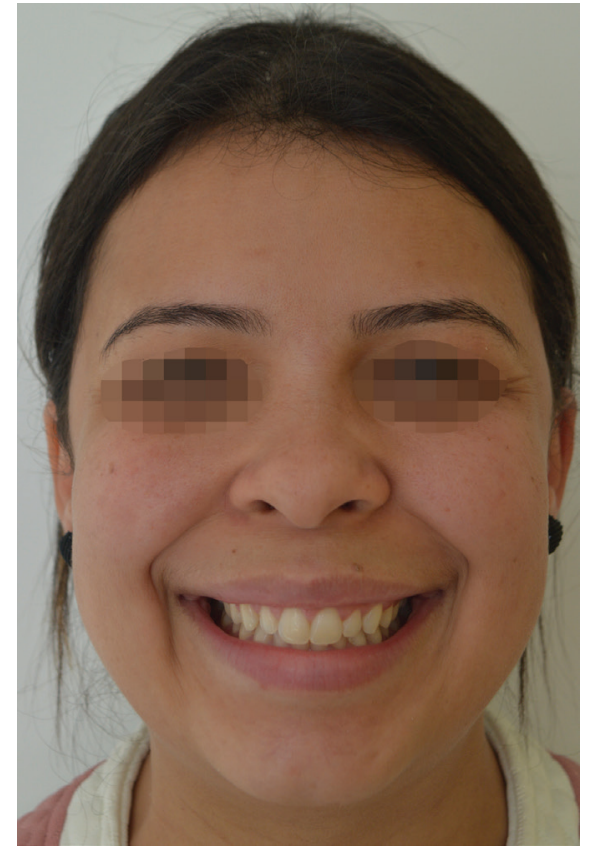

Figura 14: Resultado estético após 15 dias da aplicação da toxina botulínica. Observar a coincidência, no ato do sorriso, entre a margem inferior do lábio superior e a margem cervical nos dentes incisivos centrais superiores
Na mesma consulta, foi aplicada a toxina botulínica. Previamente a aplicação da toxina botulínica, a superfície da pele foi desinfetada com álcool etílico, evitando-se a infecção local e removendo-se a oleosidade da mesma. Posteriormente foi aplicado anestésico tópico dermatológico (Emla ${ }^{\circledR}$, Astra, São Paulo, Brasil) com o propósito de promover conforto durante o procedimento. A toxina botulínica tipo A (Botox ${ }^{\circledR} 200$ unidades, Allergan, Westport, Irlanda) foi diluída em $2 \mathrm{ml}$ de solução salina, de acordo com as normas do fabricante, e injetadas 2 unidades no sítio preconizado, lateralmente a cada narina. Após a aplicação, a paciente foi orientada a não abaixar a cabeça nas primeiras 4 horas e não realizar atividades físicas por 24 horas após o procedimento.

Após 15 dias, a paciente foi avaliada apresentando a deiscência uniforme do lábio superior. Ao sorrir, a margem do lábio superior coincidiu com a margem gengival dos incisivos centrais superiores (Figura 14). Não foram reportados efeitos colaterais ou queixas. A paciente foi orientada quanto a recorrência do sorriso gengival após, em média, de 4 a 6 meses da aplicação.

\section{DISCUSSÃO}

A toxina botulínica tem se tornado um excelente meio auxiliar no tratamento de diversas desordens odontológicas. Apesar de ser conhecida pela utilização cosmética na redução de linhas hipercinéticas faciais, também pode ser empregada com fins terapêuticos, em casos de bruxismo, disfunção temporomandibular, hipertrofia do masseter e exposição gengival acentuada ${ }^{3-13}$.

O sorriso gengival, é conceituado pela exposição de mais de $3 \mathrm{~mm}$ de tecido gengival durante o sorriso ${ }^{3,7,9,12}$, sendo frequentemente encontrado em mulheres ${ }^{12}$. A maior predominância pelo gênero feminino pode ser explicada pelo fato de pacientes do gênero masculino apresentarem a linha do sorriso mais baixa ${ }^{4,7}$.

Diversas etiologias foram sugeridas ao sorriso gengival como o excesso vertical da maxila $a^{4-8,10,11}$, erupção passiva tardia ${ }^{4,8,9,11}$, hiperfunção dos músculos envolvidos no sorriso $^{5,6,8,9,11}$ e comprimento reduzido da coroa clínica dos dentes ${ }^{1-3,9}$, que podem ocorrer isoladamente ou em conjunto, e determinam o tipo de tratamento a ser empregado.

No sorriso gengival causado pela hiperfunção muscular foi indicada a aplicação de toxina botulínica, sendo o tratamento de primeira escolha pela facilidade e segurança das aplicações, efeito rápido, além de ser um método mais conservador quando comparado aos procedimentos cirúrgicos (miectomia ou osteotomia Le Fort I) ${ }^{3-13}$. 
A atividade do sorriso é determinada por diversos músculos faciais, como o elevador do lábio superior e da asa do nariz, zigomático menor e maior, do ângulo da boca, orbicular da boca e risório ${ }^{3-8,10-12}$. Dentre eles, os três primeiros desempenham maior função e determinam a quantidade de elevação labial, devendo ser, portanto, os músculos afetados pela injeção da toxina. As fibras destes músculos convergem para a mesma área, formando um triângulo, sugerindo-se que o ponto de eleição adequado compreenda os 3 músculos em uma única injeção. A toxina ao ser injetada, pode se espalhar em área de 10 a $30 \mathrm{~mm}$, permitindo o alcance efetivo ${ }^{4,7}$. O local de injeção proposto foi lateralmente a asa do nariz $z^{3-6,10-12}$. Ao ser injetada em locais pré-determinados, a toxina diminui a contração dos músculos responsáveis pela elevação do lábio superior, reduzindo a exposição gengival ${ }^{3-13}$.

Cada músculo envolvido na elevação do lábio superior apresenta uma função durante a atividade do sorriso. Os locais para as injeções são determinados pela contração de grupos musculares específicos, que resultam em diferentes áreas de visualização gengival. Diversas classificações foram propostas ao sorriso gengival: anterior, posterior, misto e assimétrico, envolvendo grupos musculares diferentes ${ }^{4,12}$. $\mathrm{O}$ sorriso gengival anterior deve ser tratados com a técnica convencional, com aplicações lateralmente a asa do nariz. Nos pacientes com sorriso gengival posterior, a aplicação da toxina deve envolver os músculos zigomáticos maior e menor, com aplicação da toxina em dois pontos diferentes: no ponto de maior contração do sulco nasolabial durante a atividade do sorriso, e o segundo ponto, $2 \mathrm{~cm}$ lateralmente ao primeiro, ao nível da linha do tragus. Aos pacientes que apresentam sorriso gengival misto, a aplicação da toxina deve ser realizada em todos os pontos mencionados acima. Entretanto, a dose deve ser reduzida a 50\% no ponto lateral a asa do nariz ${ }^{7}$. Em casos de assimetria labial, que ocorre por diferenças na atividade muscular ${ }^{4}$, os pacientes devem receber injeções com doses diferentes em cada lado da face $\mathrm{f}^{7,12}$.

A toxina botulínica do tipo A é um pó hidrofílico, armazenado a vácuo, estéril e estável ${ }^{3,8,10}$. A reconstituição ocorre a partir da injeção suave do diluente (cloreto de sódio $0,9 \%$ ) no interior do frasco, devendo ser armazenada de 2 a $8^{\circ} \mathrm{C}$, e utilizada em 4 a 8 horas, com o propósito de garantir sua eficácia ${ }^{3,11}$.

Os efeitos clínicos apresentam-se em 2 a 10 dias após a injeção, e o efeito máximo visível ocorre após 14 dias da injeção ${ }^{3,4,10}$, com duração de aproximadamente 3 a 6 me$\operatorname{ses}^{3,7,8,11}$.

A injeção da toxina botulínica, apesar de ser um procedimento simples e seguro, pode estar associada a alguns eventos adversos como dor no local da injeção, hematomas, infecção, edema, disfonia, disfagia, ptose ou alongamento do lábio superior e assimetria do sorriso. O profissional deve estar atento em relação a posologia, precisão da técnica e localização da puntura ${ }^{3,7,8,11,13}$. No presente relato, não foram reportadas queixas ou alterações decorrentes da aplicação.

As contraindicações da utilização da toxina botulínica são a gestação; lactação; hipersensibilidade (alergia) à própria toxina botulínica, lactose e albumina; doenças musculares e neurodegenerativas (miastenia gravis, esclerose lateral amiotrófica, Síndrome de Eaton-Lambert e doença de Charcot); e uso simultâneo de antibiótico aminoglicosídico, que pode potencializar a ação da toxina ${ }^{3,11}$.

No presente relato, o resultado alcançado foi satisfatório à harmonia do sorriso da paciente pela associação dos tratamentos - gengivoplastia e aplicação da toxina botulíni- 
ca tipo A. A instituição de tratamentos isolados poderia não culminar na excelência do resultado angariado. A priori, a criação do novo zênite dentário durante a realização da gengivoplastia, promoveu a nova arquitetura dentária, favorecendo a harmonia dento-gengivo-facial da paciente. Subsequentemente, a aplicação da toxina botulínica tipo A amenizou o sorriso gengival, pela própria deiscência uniforme do lábio superior, promovendo ainda suavidade às linhas faciais do sorriso, como pode ser observado no sulco nasogeniano, adjacente às narinas, comparando-se as Figuras 1, 11 e 14.

\section{CONCLUS ÃO}

Mesmo apresentando efeito temporário na correção do sorriso gengival, a aplicação da toxina botulínica é uma alternativa menos invasiva, rápida, segura e eficaz, que produz resultados harmônicos e agradáveis quando aplicada em músculos alvo, respeitando a dose apropriada e o tipo de sorriso. Portanto, a toxina botulínica é um complemento útil na melhora estética do sorriso e fornece melhores resultados quando associada à gengivoplastia, podendo ser mais uma opção terapêutica ao alcance do cirurgião-dentista, na finalização e complementação dos seus casos.

\section{REFERÊNCIAS}

1. Pedron IG, Utumi ER, Tancredi ARC, Perrella A, Perez FEG. Sorriso gengival: cirurgia ressectiva coadjuvante à estética dental. Rev Odonto 2010; 18(35):87-95.

2. Pedron IG, Utumi ER, Silva LPN, Moretto EML, Lima TCF, Ribeiro MA. Cirurgia gengival ressectiva no tratamento da desarmonia do sorriso. Rev Odontol Bras Central 2010; 19(48):87-91.

3. Pedron IG. Toxina botulínica - Aplicações em Odontologia. 1.Ed. Florianópolis: Ponto; 2016.

4. Hwang WS, Hur MS, Hu KS, Song WC, Koh KS, Baik HS, et al. Surface anatomy of the lip elevator muscles for the treatment of gummy smile using botulinum toxin. Angle Orthod 2009; 79(1):70-7.

5. Campos RM, Dias Jr JP, Barros FC, Maia MLP, Shitsuka C, Pedron IG. Smile harmony after dental implant rehabilitation optimized by application of botulinum toxin. Scientific Archives of Dental Sciences 2020; 3(4):01-04. 6. Pedron IG, Cerri A, Medeiros JMF. Atual paradigma da Odontologia: harmonização da estética dentogengivofacial. Rev Assoc Paul Cir Dent 2020; 74(1):58-62.

7. Mazzuco R, Hexsel D. Gummy smile and botulinum toxin: A new approach based on the gingival exposure area. J Am Acad Dermatol 2010; 63(6):1042-51.

8. Polo M. Botulinum toxin type A in the treatment of excessive gingival display. Am J Orthod Dentofacial Orthop 2005; 127(2):214-8.

9. Mangano A, Mangano A. Current strategies in the treatment of gummy smile using botulinum toxin type A. Plast Reconstr Surg 2012; 129(6):1015e.

10. Indra AS, Biswas PP, Vineet VT, Yeshaswini T. Botox as an adjunct to orthognathic surgery for a case of severe vertical maxillary excess. J Maxillofac Oral Surg 2011; 10(3):266-70.

11. Jaspers GWC, Pijpe J, Jansma J. The use of botulinum toxin type A in cosmetic facial procedures. Int J Oral Maxillofac Surg 2011; 40(2):127-33.

12. Sucupira E, Abramovitz A. A simplified method for smile enhancement: botulinum toxin injection for gummy smile. Plast Reconstr Surg 2012; 130(3):726-8.

13. Niamtu J 3rd. Botox injections for gummy smiles. Am J Orthod Dentofacial Orthop. 2008; 133(6):782-3. 